\title{
EVOLUTION OF LOCAL SCOUR AROUND A COLLARED MONOPILE THROUGH TIDAL CYCLES
}

\author{
Dave McGovern'1, Suzana Ilic², Andrew Folkard², Stuart McLelland ${ }^{3}$ and Brendan Murphy ${ }^{3}$ \\ This paper presents the results of an experiment designed to assess the time-development of scour around an offshore \\ wind turbine collared monopile over a number of tidal cycles. One collar shape and location was investigated. The \\ scour developed more slowly and the scour depth was shallower than for the case of a smooth monopile throughout \\ the majority of the first half-cycle. This difference reduced quite rapidly during the second half-cycle and the scour \\ depth at the end of two tidal cycles was essentially the same as for the smooth monopile. The time development of the \\ scour was compared with results from existing empirical models for the time-development of scour under \\ unidirectional flow. As expected, these models give a much smoother evolution of scour and different scour rates \\ than those measured. Time variation in scour depth was better reproduced with a simplified approach for prediction \\ of the time-varying development of scour. This also highlighted a problem with estimation of the time scale for the \\ development of the equilibrium scour depth. Further investigations are needed before this alternative scour protection \\ is completely rejected
}

Keywords: scour; scour reduction; offshore wind farms; collared monopile; scour in tidal flow

\section{INTRODUCTION}

\section{Scour in tidal environment}

A significant issue associated with the construction of offshore wind farms is the problem of scour of the sediment on the sea bed around the base of the wind turbine supporting structures. Despite numerous studies of scour in uni-directional flow conditions (e.g. Whitehouse, 1998, Sumer et al., 2001), the effect of tidal flow on scour development has been little researched (e.g. Escarameia, 1998, Margheritini et al., 2007 and McGovern, 2011). During a tidal cycle the flow reverses and the scour will develop in two directions. There will also be some backfilling, which will affect the rate of growth for scour hole. In addition, variation in velocity and water depth during a tidal cycle causes the flow intensity parameter $\mathrm{U} / \mathrm{Uc}$ to change between live-bed $(\mathrm{U} / \mathrm{Uc}>1)$ and clear-water $(\mathrm{U} / \mathrm{Uc}<1)$ regimes, where sediment moves over the whole bed and only near the structure respectively. This in turn affects the time development of scour and the depth of scour.

Escarameia (1998) conducted a series of laboratory experiments studying the scour depth and timedevelopment of scour under reversing currents typical for estuarine environments. Velocities and water depths were varied independently to determine their individual effects on scour depth. Equilibrium scour depths were found to be lower under reversing than unidirectional currents due to infilling of sediment back into the scour hole when flow reversed. Maximum scour depths were found to occur under live bed conditions.

Margheritini (2007) approximated tidal flow in their experiments of scour by reversing currents of the same magnitude, representing maximum tidal velocity, in constant water depth. They found that the equilibrium scour hole was symmetrical in shape and that the volume of scoured material was larger than in the uni-directional flow case. In case of strong tidal flow, Jensen (2006, reported in Harris et al. 2010) found that the equilibrium scour depth was the same as that under steady flow conditions.

Experiments which simulated tidal flow with time-varying reversing currents (McGovern 2011), as described in the experimental set-up section below, found results similar to those of Escarameia (1998). The equilibrium scour hole around a smooth monopile was shallower under reversing currents than unidirectional currents, and clear-water and live-bed regimes generated distinctly different timedevelopments of the scour hole.

\section{Models for prediction of time evolution of scour}

Prediction of scour has been mainly focused on prediction of the equilibrium scour depth and, to a lesser extent, on prediction of the time evolution of scour. In conditions with oscillating currents, such as in marine environments, prediction of the time evolution of scour can be important. For example, these predictions can be useful during deployment of an offshore wind farm, in particular for

\footnotetext{
${ }^{1}$ Department of Civil and Environmental Engineering, National University of Singapore, Block E1A, \#07-03, No.1

Engineering Drive 2, 117576, Singapore

${ }^{2}$ Lancaster Environment Centre, Lancaster University, Farrer Avenue, Lancaster LA1 4YQ, UK

${ }^{3}$ Department of Geography, University of Hull, Cottingham Road, Hull, UK
} 
installation of cables once the mounts for offshore turbines are deployed (Harries et al, 2010). Despite efforts made in developing time-scale scour models for time-varying currents (e.g. Whitehouse, 1998; Nielsen and Hansen, 2007), most models are developed for steady flow conditions. Two such models will be considered here. The first model (Whitehouse, 1998) defines the scour depth $S(t)$ as a function of time with the following equation:

$$
S(t)=S_{e}\left[1-\exp \left(\frac{-t}{T_{s}}\right)^{n}\right]
$$

where $\mathrm{T}_{\mathrm{s}}$ is the time-scale of the scour process given by (2), $S_{e}$ is the equilibrium scour depth given by (4), and $n$ is a power normally taken to be 1 (Sumer et al., 1992a).

The time scale of scour for live-bed conditions is calculated using (2), which was determined from an extensive series of tests (Sumer et al, 1992):

$$
T^{*}=\frac{\left[g(s-1) d_{50}^{3}\right]^{1 / 2}}{D^{2}} T_{s}
$$

where $d_{50}$ is the median sediment grain size $(\mathrm{m}), g$ is the gravitational acceleration $\left(\mathrm{m} / \mathrm{s}^{2}\right), D$ is the external diameter of pile $(\mathrm{m})$ and $T^{*}$ is the dimensionless time-scale for steady currents given as:

$$
T^{*}=\frac{\delta \theta^{-2.2}}{2000 D}
$$

where $\delta$ is the boundary layer thickness (m), assumed to be the flow depth for tidal flow and $\theta$ is the Shields parameter.

A number of empirical models have been developed for the prediction of equilibrium scour depth in unidirectional steady flows. Breusers et al. (1977) developed an empirical equation based on various measurements and observations of scour holes including those under tidal flow. This is suitable for clear- and live-bed conditions and is one of the most widely used models. The equation is given as:

$$
S_{e}=c f K_{1} K_{2} K_{3} K_{4} D \tanh \left(\frac{h}{D}\right)
$$

where $c f$ is a coefficient usually equal to $1.5 ; K_{l}$ is the correction factor for pile nose shape; $K_{2}$ is the correction factor for the angle of approach of the flow; and $K_{3}$ is the correction factor for bed conditions which varies between 0 and 1 depending on flow intensity parameter $U / U_{c r}$ (e.g. see Harris et al. 2010 for further details). Jensen (2006, as reported by Harris et al. 2010) recommended this model for the prediction of scour depth under tidal flow with $c f=1.25$ and this was used in this paper.

The second model, developed by Melville and Chiew (1999), defines the development of scour with time $S(t)$ as:

$$
S(t)=\exp \left[-0.03\left|\frac{U_{c r}}{U} \ln \left(\frac{t}{T_{s}}\right)\right|^{1.6}\right] S_{e}
$$

where $U$ is the depth-averaged current velocity $(\mathrm{m} / \mathrm{s}), U_{c r}$ is the threshold depth-averaged current velocity $(\mathrm{m} / \mathrm{s})$ and the other parameters are defined above.

Melville and Chiew (1999) defined the time development of scour to be a function of the flow intensity $U / U_{c r}$, relative water depth $h / D$ and sediment coarseness $d_{50} / D$. The formula given below provides an estimation of the time scale of scour in days and is only suitable for clear water conditions (i.e. $U / U c \leq 1)$ : 


$$
T_{s}=30.89 \frac{D}{U}\left(\frac{U}{U_{c r}}-0.4\right)\left(\frac{h}{D}\right)^{0.25}
$$

where $h$ is water depth (m) and other parameters as defined above.

The equilibrium scour depth is calculated using the Colorado State University (CSU) equation (Richardson et al., 1993), which is suitable for determining equilibrium scour depth in the clear-water, transition and live-bed conditions:

$$
S_{e}=2 K_{1} K_{2} K_{3} h F r^{0.43}\left(\frac{D}{h}\right)^{0.65}
$$

Where $F r$ is the Froude number defined as $F r=U / \mathrm{V} h ; K_{l}$ is the correction factor for cylinder nose shape ( $=1$ for circular cylinder); $K_{2}$ is the correction factor for angle of attack of flow (=1 for circular cylinder); and $K_{3}$ is the correction factor for bed conditions.

Harris et al. (2010) developed the Step model based on a time-stepping approach. They applied the method of Sumer et al. (1992), which describes scour for both steady and time-varying flows (equations 1-4). The equilibrium scour depth remains constant under steady and varies under time-varying flows. It takes into account the scour depth at each particular time relative to the predicted equilibrium scour depth and adjusts the time-scale accordingly. They also acknowledged the importance of prediction of the time-scale parameter, which will be addressed in the discussion section. Back-filling is taken into account by assuming the same approach as for scouring. The model was tested with laboratory and field data and it was found to reproduce satisfactorily the measured time-varying scour depths.

\section{Scour reduction}

Scour protection around structures, including offshore wind turbines, consists of a choice between static and active protection. An example of static protection is bed armouring, which prevents sediments from being entrained and transported. Active protection involves the modification of the flow around the mount of the wind turbine, which results in reduction rather than increase of the bed shear stress. Examples of flow modification techniques include attaching collars (e.g. Dey et al., 2006) or helical strakes to the monopile, or installing splitter plates or slots into the monopile (e.g. Odgaard and Wang, 1987). Active protection can be more effective and usually requires less investment in time and resources to construct and maintain. Therefore it is an appealing solution to the problem of scouring.

The performance of collars and helical strakes are reasonably well researched in clear water river flow environments, and their ability to reduce scour is well documented (e.g. Dey et al. 2006). As most offshore wind turbines are deployed in shallow and intermediate waters, they are mounted on monopiles on which collars and helical strakes might be easy to install. The installation of a collar close to or just below the bed surface may reduce the flow intensification around monopiles and the resulting scour in tidal flow. There is, to the authors' knowledge, no investigation of these monopile designs in live-bed conditions and tidal flow of variable water velocity and depth. McGovern (2011) conducted detailed flow measurements around a collared and a helical cylinder deployed on a rigid bed in laboratory experiments of tidal flow. A slightly greater reduction in the strength of the downflow was recorded for collared than helical monopile. Taking this into account and the fact that collars are easier to install, the effect of a collared monopile on development of scour hole was investigated in the mobile bed experiment.

The following section gives details of the experimental set-up, which is followed by a description of the measured time-development of scour around a collared monopile. These results were compared with those obtained in experiments around a smooth monopile (McGovern, 2011). The measurements are also compared with predictions from the models described above, and the results are discussed in the final section.

\section{EXPERIMENTAL SET-UP}

A laboratory flume experiment was conducted using both rigid and mobile beds in an $11 \mathrm{~m}$ long and $1.2 \mathrm{~m}$ wide flume at the University of Hull's Deep Facility, UK. The experimental conditions had length scales $1 / 20^{\text {th }}$ of those of the prototype. In addition, the sediment was scaled using a fixed ratio $U / U_{c}$. These two criteria yielded a monopile (cylinder) of diameter $D=200 \mathrm{~mm}$ and sediment size 
$d_{50}=0.135 \mathrm{~mm}$. The collared monopile had five $0.025 \mathrm{~m}$ wide $2 \mathrm{~mm}$ thick steel sheet horizontal collars around the circumference attached at $0.1 \mathrm{~m}$ intervals with the nearest to the bed being located at $0.1 \mathrm{~m}$ off the bed. Tidal flow was simulated by varying the flow velocity, depth and direction based on measurements of standing wave tidal flow from Liverpool Bay where several offshore wind farms are located. Reversing tidal flow was assumed to be symmetrical. The current velocities and associated water depths taken from field measurements are applied in a 'step-wise' manner. Each half-tidal cycle was split into three time-steps, represented by three different velocities, calculated as the mean value of flow velocity for each third of the half-cycle. These three reversing velocity/depth-varying flows exhibited clear-water, transitional and live-bed conditions. Following the Froude timescale criterion, each flow condition was simulated for 27 minutes resulting in one hour and 21 minutes for each halfcycle. Two complete tidal cycles were simulated at the end of which the scour depth was approaching equilibrium depth. Table 1 summarizes the simulated flow conditions.

\begin{tabular}{|c|c|c|c|c|c|c|c|c|}
\hline $\begin{array}{l}\text { Time } \\
\text { step }\end{array}$ & $\begin{array}{c}\text { Relevant } \\
\text { Tidal } \\
\text { Half } \\
\text { Cycle }\end{array}$ & $\begin{array}{l}\text { Relevant } \\
\text { Tidal } \\
\text { Stage }\end{array}$ & $\begin{array}{l}\text { Flow } \\
\text { direction }\end{array}$ & $\begin{array}{l}\text { Velocity } \\
U(\mathrm{~m} / \mathrm{s})\end{array}$ & $\begin{array}{l}\text { Water } \\
\text { depth } \\
\mathrm{h}(\mathrm{m})\end{array}$ & $\mathrm{U} / \mathrm{U}_{\mathrm{cr}}$ & $\mathrm{h} / \mathrm{D}$ & Test condition \\
\hline 1 & $1^{\text {st }}$ & Low-tide & Positive & 0.23 & 0.1 & 1.02 & 0.5 & Transition \\
\hline 2 & $1^{\text {st }}$ & Mid-tide & Positive & 0.31 & 0.2 & 1.24 & 1 & Live-bed \\
\hline 3 & $1^{\text {st }}$ & $\begin{array}{l}\text { High- } \\
\text { tide }\end{array}$ & Positive & 0.15 & 0.4 & 0.54 & 2 & Clear-water \\
\hline 4 & $2^{\text {nd }}$ & $\begin{array}{l}\text { High- } \\
\text { tide }\end{array}$ & Negative & 0.15 & 0.4 & 0.54 & 2 & Clear-water \\
\hline 5 & $2^{\text {nd }}$ & Mid-tide & Negative & 0.31 & 0.2 & 1.24 & 1 & Live-bed \\
\hline 6 & $2^{\text {nd }}$ & Low-tide & Negative & 0.23 & 0.1 & 1.02 & 0.5 & Transition \\
\hline 7 & $3^{\text {rd }}$ & Low-tide & Positive & 0.23 & 0.1 & 1.02 & 0.5 & Transition \\
\hline 8 & $3^{\text {rd }}$ & Mid-tide & Positive & 0.31 & 0.2 & 1.24 & 1 & Live-bed \\
\hline 9 & $3^{\text {rd }}$ & $\begin{array}{l}\text { High- } \\
\text { tide }\end{array}$ & Positive & 0.15 & 0.4 & 0.54 & 2 & Clear-water \\
\hline 10 & $4^{\text {th }}$ & $\begin{array}{l}\text { High- } \\
\text { tide }\end{array}$ & Negative & 0.15 & 0.4 & 0.54 & 2 & Clear-water \\
\hline 11 & $4^{\text {th }}$ & Mid-tide & Negative & 0.31 & 0.2 & 1.24 & 1 & Live-bed \\
\hline 12 & $4^{\text {th }}$ & Low-tide & Negative & 0.23 & 0.1 & 1.02 & 0.5 & Transition \\
\hline
\end{tabular}

In the rigid bed tests, the detailed flow structure was measured using Particle Image Velocimetry, whereas in the mobile bed tests presented here, the flow was measured using an Acoustic Doppler Velocimeter upstream and downstream of the pile for positive and negative flow respectively. The time development of scour was measured using a Seatek Ultrasonic Ranging System (URS). Twelve sensors were placed around the pile along the main flow axis and axis perpendicular to the flow. The sensors closest to the pile were separated from it by $6.5 \mathrm{~cm}$, and there was a radial spacing of $10 \mathrm{~cm}$ between sensors. Figure 1 shows a sensor layout.

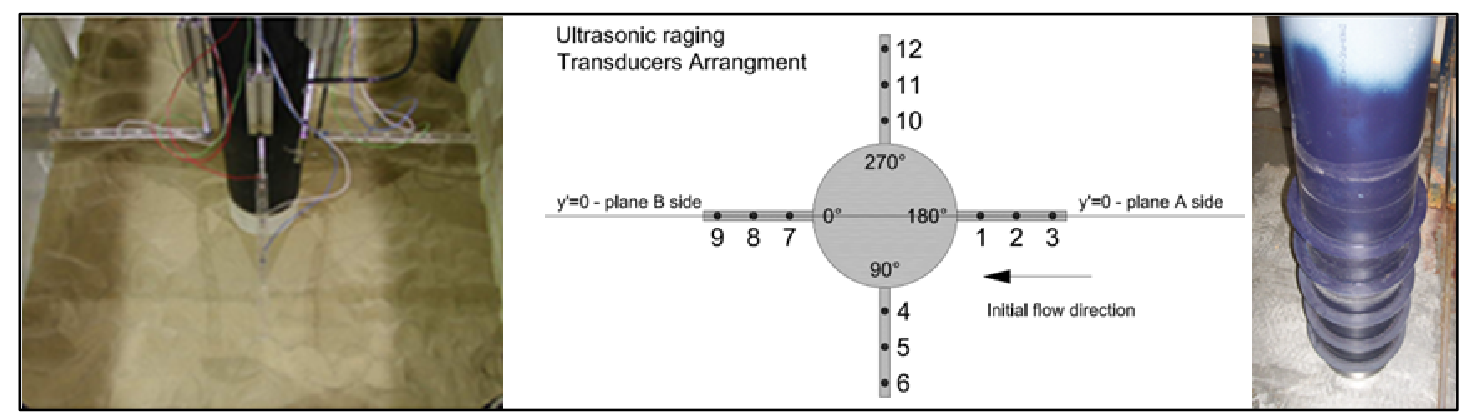

Figure 1. Left panel shows the mounting of the URS around cylinder, mid panel shows the locations of sensors around the cylinder and right panel shows the collared monopile.

The changes in the bed were ensemble averaged over 20 individual readings recorded at $1 \mathrm{~s}$ intervals with the 3 highest and 3 lowest readings discarded. In addition the bed changes around the cylinder were measured at the end of two tidal cycles using a laser distance measurer. 


\section{RESULTS}

\section{Time development of scour around collared monopile}

Figure 2a-d shows the time development of a scour hole upstream and downstream of a collared monopile during each tidal half-cycle. Time-series readings taken at 5, 10, 15, 20 and 25 minutes are shown. However, due to the presence of high amount of suspended sediment downstream of the cylinder, only readings at the beginning and at the end of each test (flow condition) are plotted for downstream locations. During the first time step, the greatest amount of scour occurred in the lateral planes, which are not shown here. This was not surprising, as the largest bed shear stresses were recorded at the sides (axis perpendicular to the flow) of the cylinder in the rigid bed experiment (McGovern, 2011). There was very limited erosion upstream of the cylinder and deposition occurred downstream of the cylinder. The greatest depth was achieved in the second time step during flow conditions with largest velocities (live-bed conditions). A depth of $4.25 \mathrm{~cm}(0.21 \mathrm{D})$ was recorded along the centerline, immediately downstream of the cylinder where sediment was deposited in the first time step. As the velocity reduced in the third time step, the changes in scour development were minimal. Once again, the deepest hole developed at the sides of the cylinder where a depth of $6.66 \mathrm{~cm}(0.33 \mathrm{D})$ was recorded.

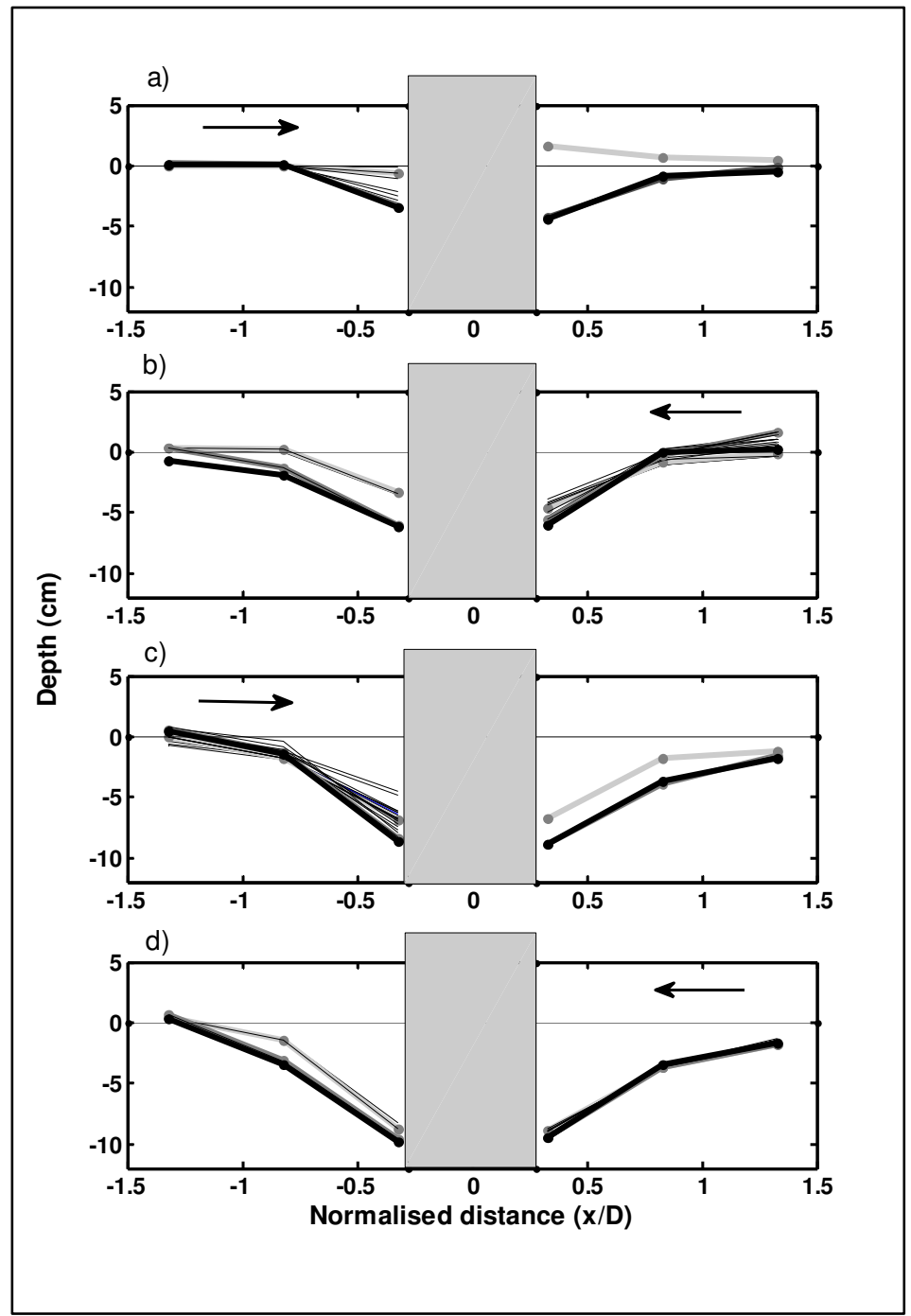

Figure 2. Time evolution of scour depth around the collared monopile at different tidal stages. The bold light gray line corresponds to the first time step, the bold dark gray line to the second time step and the bold black line to the third time step in each half-tidal cycle. Light black lines correspond to the recordings taken every $5 \mathrm{~min}$.

Figure 2b) shows changes due to reversing currents. There is minimal or no change during time step four which has the lowest flow velocity. During the time step five, scour depth increases in all 
planes. The scour hole downstream of the cylinder becomes similar in depth to that upstream and expands its length. At the final step in this second half-cycle, there is scouring further downstream of the cylinder and erosion of sediment deposited upstream of cylinder in the previous time step. The final shape of scour hole remains asymmetrical. There is narrowing of the scour hole upstream of the cylinder and widening downstream of the cylinder when the flow is reversed in time step seven (Figure $2 \mathrm{c})$ ). The depth of scour increased all around the cylinder in time step eight by about $2 \mathrm{~cm}$. There was only a very small change in scour depth upstream of the cylinder in time step nine, resulting in an asymmetrical scour hole which has almost the same depth upstream and downstream of the cylinder as at the end of the third half-cycle. The scour depths at the side of the cylinder were $2-3 \mathrm{~cm}$ larger. In the final half-cycle (Figure 2d)), there is a marginal increase in the width of the scour hole in all planes. The scour depth both upstream and downstream of the cylinder is more or less the same $(9.45$ and $9.86 \mathrm{~cm}$; or $0.47 \mathrm{D}$ and $0.49 \mathrm{D})$ and closer to the depths recorded at the sides $(10.13$ and $10.61 \mathrm{~cm}$; or $0.5 \mathrm{D})$. The shape of the scour hole has become more symmetrical.

During all time steps it was observed that sediment was deposited on the lower collar on the downstream side. Clearly, suspended sediment was caught in a downstream vortex which was observed in the rigid bed experiment (McGovern 2011). Significant backfilling was observed due to flow reversal. However, this did not seem to have an effect on the scour depth development upstream or downstream of the monopile. This has more effect on the side of the monopile where scour depths were reduced when flow reversed (Figure 3).

\section{Comparison of scour hole developments for collared and smooth monopile}

The results are compared with those from the experiment with a smooth monopile (McGovern, 2011). The time development of scour depths at the four locations closest to the collared and smooth monopiles is plotted in Figure 3. For both monopiles, the initial scour development occurs at the side of the cylinder. However the depth was larger in case of the smooth cylinder by $1 \mathrm{~cm}$. There was an increase in scour depth during time step two for both cases, but again this was more pronounced for the smooth cylinder. The scour growth rate up to time step eight is slower for the collared monopile than for the smooth monopile, after which, the collar is clearly no longer having a reducing effect on the depth of scour. The summary of differences in scour depth at four locations closest to the cylinder is given in Table 2.

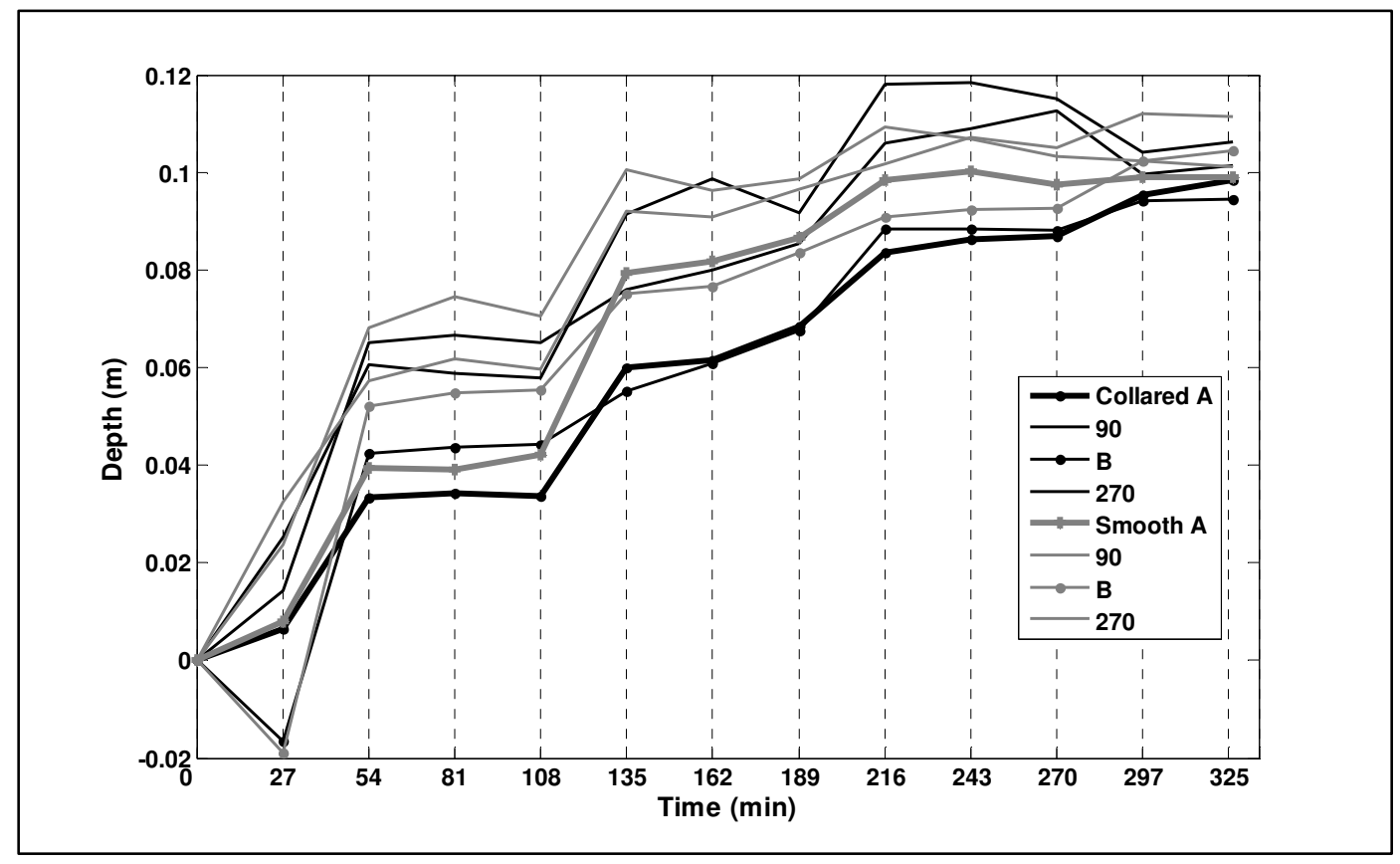

Figure 3. Time evolution of scour depth around the collared and the smooth monopile for two tidal cycles. 


\begin{tabular}{|c|c|c|c|c|}
\hline Probe & $\begin{array}{l}\text { Time } \\
\text { step } 3\end{array}$ & $\begin{array}{l}\text { Time } \\
\text { step } 6\end{array}$ & $\begin{array}{l}\text { Time } \\
\text { step } 9\end{array}$ & $\begin{array}{l}\text { Time } \\
\text { step } 12\end{array}$ \\
\hline 1 & 0.005 & 0.020 & 0.014 & 0.0004 \\
\hline 4 & 0.008 & 0.016 & -0.002 & -0.0003 \\
\hline 7 & 0.011 & 0.016 & 0.004 & 0.0099 \\
\hline 10 & 0.003 & -0.008 & -0.011 & 0.0052 \\
\hline
\end{tabular}

At the end of test, bed changes were measured using a laser depth profiler. The central profiles for the collared monopile and for the smooth monopile scour hole are compared in Figure 4. The morphologies and scour depths are quite similar. The depths close to the monopile were estimated for the collared and the smooth monopile to be between 12 and $14 \mathrm{~cm}$.

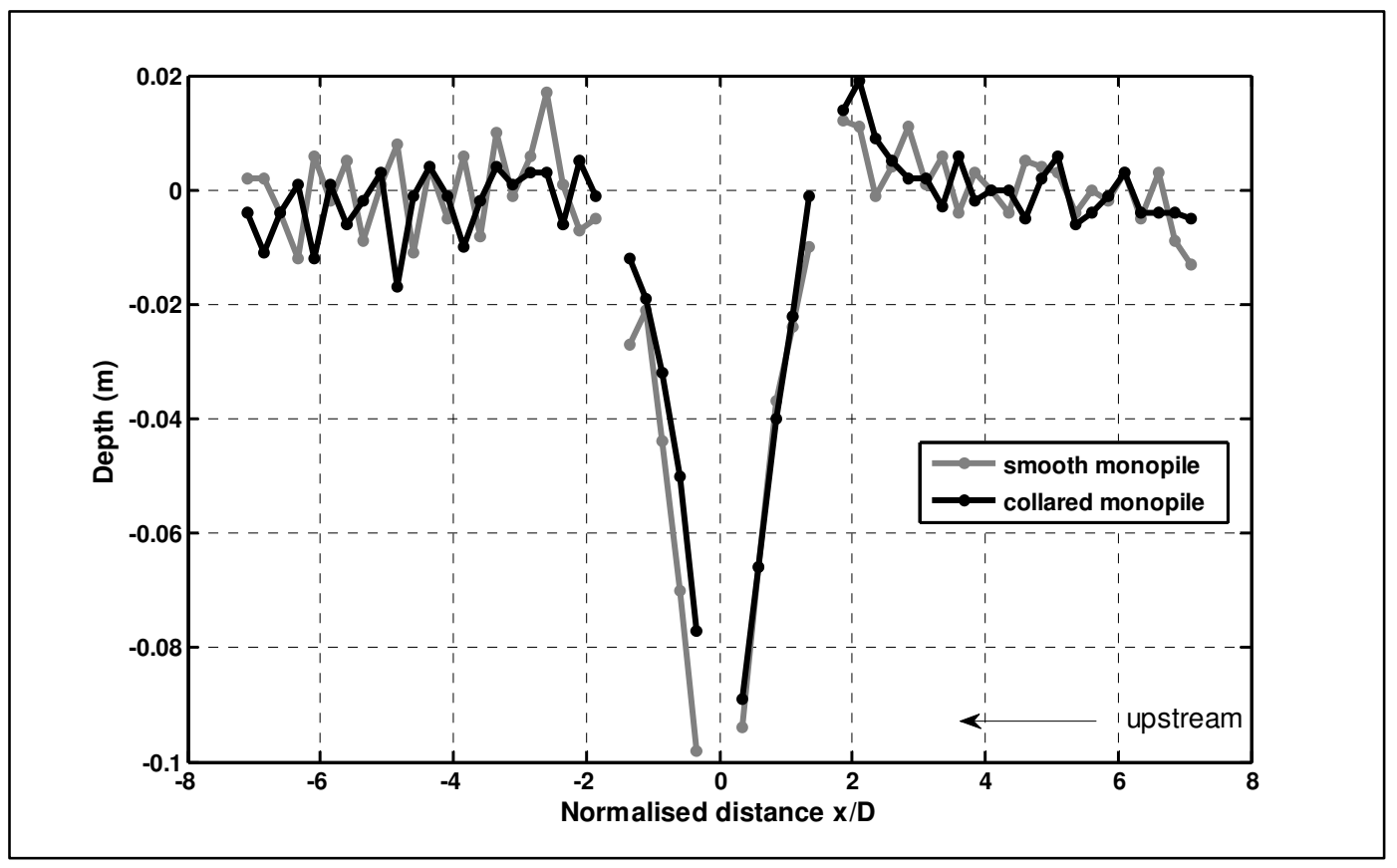

Figure 4. Central bed profile of the collared and the smooth monopile scour holes at the end of two tidal cycles.

\section{Prediction of time-development of scour}

The theoretical time-development of scour was calculated using Sumer et al. (1992), given by equations 1-4, and Melville and Chiew's (1999) approaches, given by equations 5-7, developed for steady unidirectional flows. Sumer's approach was used with flow conditions at mid-tide and low-tide (live-bed and transition) and Melville's approach was used with high-tide and low-tide conditions (clear-water and transition). A summary of obtained predictions for equilibrium scour depths and time scales of scour development is given in Table 3 below.

\begin{tabular}{|c|c|c|c|c|c|c|c|}
\hline $\begin{array}{l}\text { Tidal } \\
\text { Stage }\end{array}$ & Conditions & $\begin{array}{l}\text { Water } \\
\text { depth } \\
\text { (m) }\end{array}$ & $\begin{array}{l}\text { Flow } \\
\text { velocity } \\
(\mathrm{m} / \mathrm{s})\end{array}$ & $\begin{array}{l}\text { Equ. depth } \\
(\mathrm{m}) \\
\text { Equation } \\
(7)\end{array}$ & $\begin{array}{l}\text { Equ. depth } \\
(\mathrm{m}) \\
\text { Equation } \\
(4)\end{array}$ & $\begin{array}{l}\text { Time scale } \\
\text { (s) } \\
\text { Equation } \\
(6)\end{array}$ & $\begin{array}{l}\text { Time scale } \\
(\mathrm{s}) \\
\text { Equation } \\
(2,3)\end{array}$ \\
\hline $\begin{array}{l}\text { Low-tide } \\
\text { Mid-tide } \\
\text { High-tide }\end{array}$ & $\begin{array}{l}\text { Transition } \\
\text { Live-bed } \\
\text { Clear-water }\end{array}$ & $\begin{array}{l}0.1 \\
0.2 \\
0.4\end{array}$ & $\begin{array}{l}0.23 \\
0.31 \\
0.15\end{array}$ & $\begin{array}{l}0.17 \\
0.17\end{array}$ & $\begin{array}{l}0.12 \\
0.19\end{array}$ & $\begin{array}{l}1206686.2 \\
612794.6\end{array}$ & $\begin{array}{l}475.79 \\
395.61\end{array}$ \\
\hline
\end{tabular}


From Table 3, it is evident that different models give different predictions for the same flow conditions. While the difference is relatively small for the equilibrium scour depth, it is quite significant for the calculated time scale resulting in different predictions of the time development of scour. Figure 5 shows the time development of scour calculated using Sumer's approach and low-tide flow conditions (SB_T) and Melville and Chiew's approach using low-tide and high-tide flow conditions (MC_T and MC_C). These are plotted together with measured scour depths after each time step. In addition calculations are made using Sumer's approach and equilibrium scour depth calculated by (7) for midtide flow conditions (SC-L) and Melville's approach and equilibrium scour depth calculated by (4) for low-tide flow conditions (MB-T). The prediction from the MB_T model is also shown in Figure 5.

The predictions made for live-bed conditions at mid-tide (SB_L and SC_L not shown in Figure 5) greatly overestimate the overall depth of scour. The model's rate of growth of scour depth is also faster than measured. All predictions overestimate the rate of growth for the scour depth at the start before slowing to a constant (MB-T) or more comparable rate (MC_C). Predictions for clear water conditions using Melville's approach (MC_C) appear to follow the measured time development of scour reasonably well, despite the measured rate of scour growth at the individual stages being greater than the theoretical prediction. This, in particular, was the case in the mid-tide time-steps.

There are several reasons why the models do not predict the time-development of scour in varying flow conditions well: i) the equilibrium scour depth and the rate of growth of the scour depth varies in time, and in addition there might be some infilling during flow reversals, neither of which are taken into account; ii) the time-development depends on predicted equilibrium scour depth, which is not the same as the measured depth; and iii) the predicted scour development depends on the calculated time-scale, which in the examples given here is over- or under-predicted; iv) the equilibrium depth might not be reached completely by the end of the experiment, although the measured depths converged. This is addressed further in the discussion section.

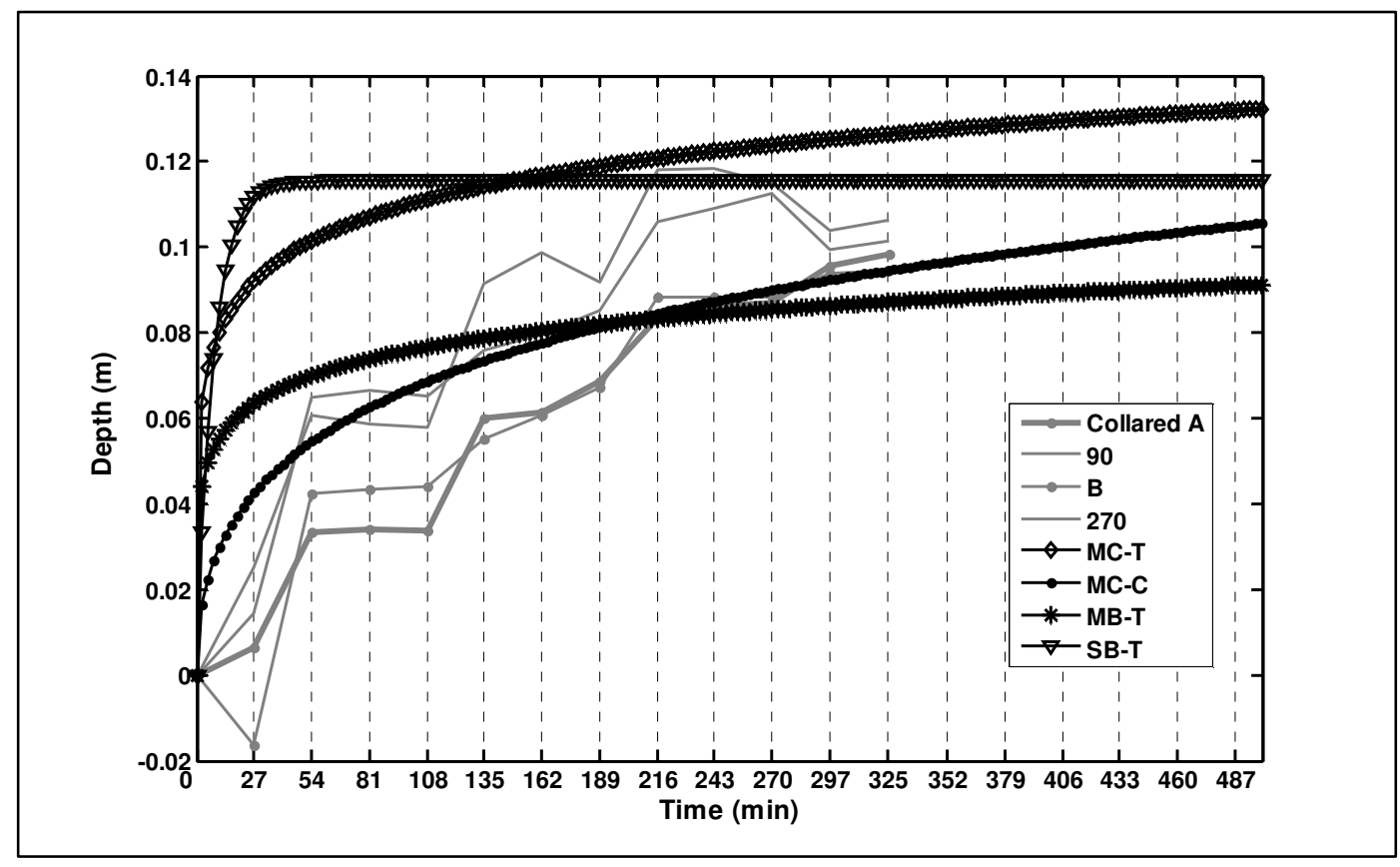

Figure 5. Time development of scour at probes one, four, seven and ten with the Melville and Chiew, (1999) curve for the low and high-tide conditions and the Sumer et al., (1992a) for the low-tide condition.

The time-varying development of scour was also calculated following the approach of Harris et al. (2010), though with some simplifications. For each tidal stage, the equilibrium scour depth and the time-scale of the scour development were calculated. The scour depth at each tidal stage was considered relative to the predicted equilibrium for that tidal stage. An assumption was made that the scour hole remains unchanged if the flow velocity is below the critical-threshold velocity for sediment movement. The critical velocity, the drag coefficients and other parameters were calculated by using equations for non-cohesive sediment given by Soulsby (1997). Here, infilling processes were not taken into account. The first estimate of the time development of scour, not shown here, was calculated using 
the equilibrium scour depth obtained from (4) with $c f=1.25$, which was greater than the measured depth. In addition, the model rate of growth for the scour depth is over-predicted and the equilibrium depth was reached after two time steps (tidal stages). Like the results obtained by the steady flow models above, this result is affected by the under-predicted time scale for the equilibrium scour depth. This was also observed by Harris et al. (2010).

As estimation of the time-scale parameter is important for providing good predictions from the model, a series of sensitivity tests was carried out to investigate how the variation in the time-scale estimates influences the model results. The time-scale estimates are dependent on a number of parameters. Here we tested sensitivity to the height of the boundary layer, grain size and the drag coefficient. The height of the boundary layer was varied from assuming it to be equivalent to the water depth, as in predictions made above, to less than the water depth. The obtained time scales for mid-tide conditions were in range 296-475s. Grain size was also varied from 0.1215 to 0.1485 and the resulting time scale varied from 392 to 398s. There are other available expressions for estimation of the drag coefficient, which can give slightly different values. Hence the drag coefficient was varied from 0.001 to 0.0031 resulting in time-scale ranges for mid-tide from 273 to 3060s. New curves describing the time-development of scour were plotted taking into account minimum, maximum and average values of all time-scales obtained by varying the parameters described here. The smallest equilibrium depth, which was closest to the measured final depth, was used for these calculations. The results are plotted in Figure 6.

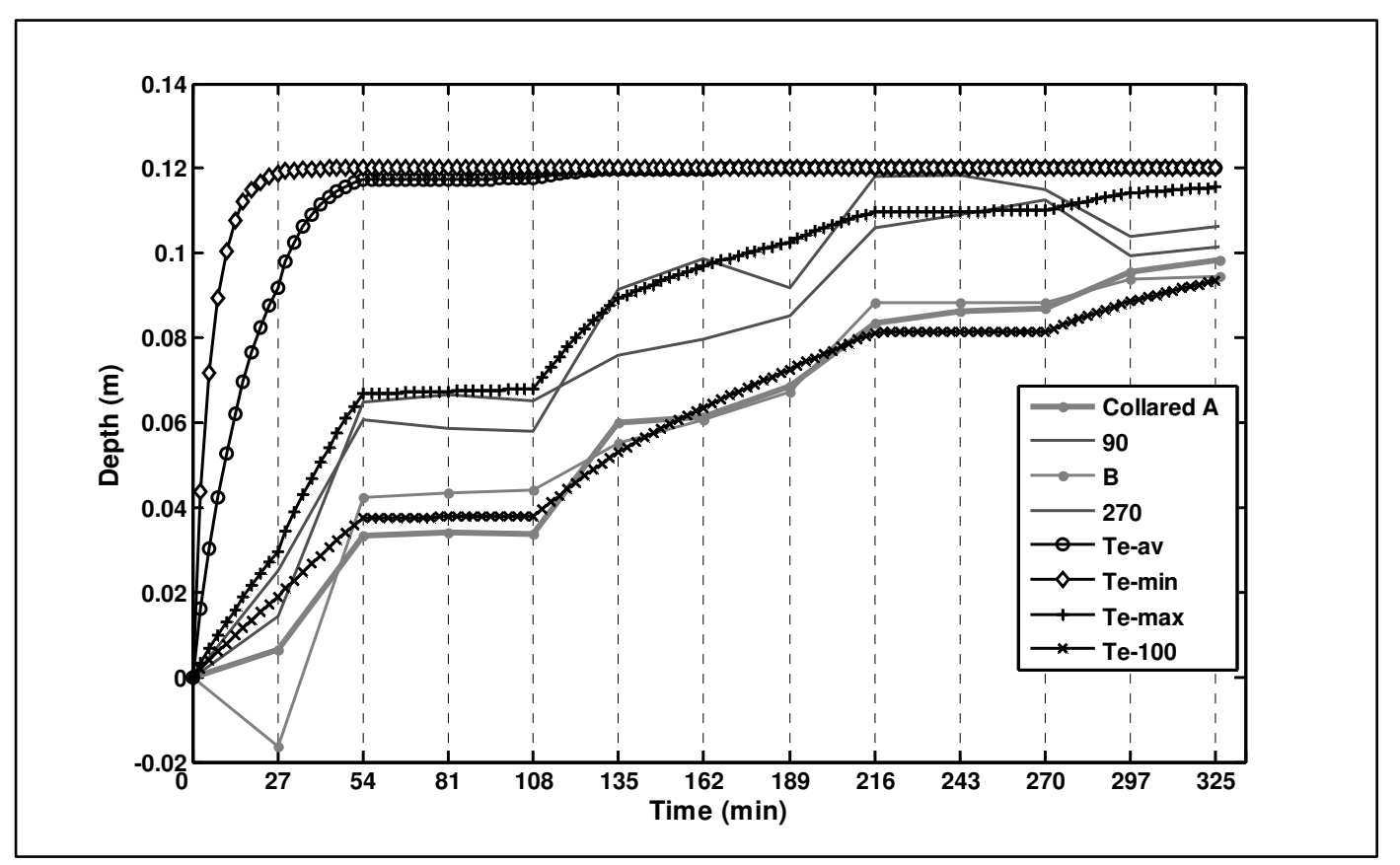

Figure 6. Predictions of the time-evolution of scour using the stepped approach.

For the average and minimum time scales, the curves are very similar and the equilibrium scour depth developed after two and one time-steps respectively. The growth rate for the scour was much faster than the measured value. For the maximum time scale, the general variation was reasonably well reproduced. The predicted rate of growth was slightly faster than the value measured upstream and downstream of the cylinder but close to those measured at the sides of the cylinder. A similar result was obtained by increasing arbitrarily the time scale twenty-fold, by replacing 2000 by 100 in (3). The new predictions of scour depths matched much closer those measured upstream and downstream of the cylinder. While the general variation of scour can be reproduced quite well with even the simplified approach presented here, these results highlight the sensitivity of the predictions to the time-scale estimate used.

\section{DISCUSSION AND CONCLUSION}

Only one collared monopile was tested in this experiment. The collars were installed above the bed with the idea that this would be less of an engineering challenge, and may yield the greatest reduction of 
scour. However, as the mobile bed results presented here show, the amount of scour at the end of the mobile bed test for the collared monopile was essentially the same as it was for the smooth monopile. This is a surprising result at first sight. However, this is probably because the scour hole has become deep enough to reduce the ability of the collar to interrupt the downflow by the extra length of monopile exposed. Furthermore, and perhaps more importantly, as the scour hole grows in size so does the horseshoe vortex (Melville, 1975) and the positioning of the collar above the bed level will not interact with the horseshoe vortex, which will form from separated flow coming off the scour hole's upstream lip allowing it to scour unimpeded.

Previous research on flow modification around bridge piers indicates that the collar may work better if positioned closer to the bed or just below the bed surface (e.g., Dey et al., 2006). The collar then prevents scour continuing below its location by providing a physical barrier between the downflow and horseshoe vortex and the sediment. The collar generally needs to have a diameter which is significantly greater than D to be most effective (e.g., Kumar et al., 1999), which may be less practical in a marine deployment. It would require installation after piling, probably by divers and would require continuous monitoring to ensure passing bed forms, storm events and the generally dynamic nature of seabed morphology does not undermine its position at the bed. The location of a collar very near to or below the surface would interfere with, and likely be damaged by, any rip rap scour protection that may also be installed. Furthermore, Kumar et al., 1999 found that although collars that are installed at the bed reduce upstream and lateral scour to in some cases zero (for a collar of size 4D), the amount of scour on the downstream side increases greatly. Collars have only been tested in clear-water conditions (for example, Dey et al., 2006 and Kumar et al., 1999), which increases uncertainty of their effectiveness in the marine environment.

Taking into account that the final equilibrium depth might not be reached by the end of two tidal cycles, the models presented here can provide reasonably good estimates of the equilibrium scour depth. However the rates of growth that they predict for the scour hole are different from those measured, mainly due to problems of estimation of the time-scale needed for the development of the equilibrium depth. In the time-varying approach based on Sumer et al. (1992), it was clear that the timescale is under-predicted. It has been noted before that the estimated time scale needs to be 'scaled down' to get more accurate predictions (Harris et al., 2010). This might be due to different conditions on the basis of which these equations are derived (e.g. unidirectional rather than tidal flow and/or different laboratory scales). Despite this limitation, the models based on empirical equations are simpler and quicker to use than the full 3D numerical simulations of the scour processes. Hence further field and laboratory measurements in varying conditions are needed to test further, and if necessary modify, the equations used for prediction of the time-development of the scour.

In summary, the scour depth around the collared monopile was consistently lower than it was for the same position and time around the smooth monopile throughout the majority of the first half-cycle. The difference is regularly between 1 and $2 \mathrm{~cm}$ less than for the smooth monopile (i.e. between $15-25$ $\%$ less depth than for the smooth monopile). The difference reduces quite rapidly during the second half-cycle when flow modifications became governed by the scour hole rather than the collars.

Nevertheless the scour depth was lower than for unidirectional flow in live-bed conditions, as in case of a smooth monopile (McGovern, 2011). It appeared mainly to be due to the inherently different scour rates that occur under different tidal flow conditions. The live-bed, mid-tide has a significantly faster rate than the low-tide (threshold flow-intensity) and high-tide (clear-water) rates. This will require more research to investigate fully but if confirmed, it will potentially reduce the amount of scour protection required and therefore the costs of scour protection.

The deployment of collars around the monopile described above is clearly not the most efficient one. The data suggests that a single, wider collar positioned closer to the bed will have more effect. Only one collar shape and location was investigated, and further investigations are needed before this alternative scour protection is completely rejected. These must take into account the following: 1) the ease of installation and monitoring, 2) the effect it may have on the monopile design, installation and cable-routing, 3) its interaction with any additional passive scour protection such as rip-rap and 4) the effect of live-bed conditions on its stability and ability to reduce scour.

\section{ACKNOWLEDGMENTS}

This work was fully funded by the UK Engineering and Physical Sciences Research Council the Supergen Wind Energy Technologies Consortium, grant EP/D034566/1. 


\section{REFERENCES}

Breusers, H.N.C., Nicollet, G., and H.W. Shen. 1977. Local scour around cylindrical piers, Journal of Hydraulic Research, IAHR, 15(3), 211-252.

Dey, S., Sumer, B. M., and J. Fredsoe. 2006. Control of Scour at Vertical Circular Piles under Waves and Current, Journal of Hydraulic Engineering, 132, 270-279.

Escarameia, M. 1998. Laboratory Investigation of Scour around Large Structures in Tidal Waters. Proceedings of 3rd International Conference on Hydro-Science and Engineering, Berlin, ICHE.

Harris, J. M., Whitehouse, R. J. S., and T. Benson. 2010. The Time Evolution of Scour around Offshore Wind Turbines, Proceedings of the Institution of Civil Engineers - Maritime Engineering, 163, 3-17.

Kumar, V., Ranga Raju, K. G., and N. Vittal. 1999. Reduction of Local Scour around Bridge Piers using Slots and Collars, Journal of Hydraulic Engineering, 125, 1302 - 1305.

Margheritini, L., Martinelli, L., Lamberti, A., and P. Frigaard. 2007. Scour Around Monopile Foundation for Off-shore Wind Turbine in Presence of Steady and Tidal Currents, Proceedings of the 30th International Conference on Coastal Engineering, World Scientific, 2330-2342.

Melville, B. W. 1975. Local Scour at Bridge Sites, Auckland University, Auckland.

Melville, B. W., and Y.M. Chiew. 1999. Time Scale for local Scour at Bridge Piers, Journal of Hydraulic Engineering, 125, 59-65.

McGovern,D. 2011. The interaction of tidal currents with offshore wind turbine monopiles: An experimental study of flow, turbulence, scour and reduction of scour around monopile. $\mathrm{PhD}$ Thesis, Lancaster University.

Nielsen, A.W. and E.A. Hansen. 2007. Time-varying wave and current-induced scour around offshore wind turbines, Proceedings of the $26^{\text {th }}$ International Conference on Offshore Mechanics and Arctic Engineering, American Society of Mechanical Engineers, 5, 399-408.

Odgaard, A. J. and Y. Wang. 1987. Scour prevention at bridge piers, Proceeding of Hydraulic Engineering National Conference, ASCE, 523-527.

Richardson, E.V., Harrison, L.J., Richardson, J.R., and S.R. Davis. 1993. Evaluating Scour at Bridges ( $2^{\text {nd }}$ ed.): Federal Highway Administration Hydraulic Engineering Circular, April 1993 revision, FHWA-IP-90-017, Washington, DC, 237 p.

Soulsby, R. L. 1997. Dynamics of Marine Sands. A Manual for Practical Applications, Thomas Telford, London.

Sumer, B. M., Whitehouse, R. R. S., and A. Torum. 2001. Scour Around Coastal Structures: a Summary of Recent Research, Coastal Engineering, 44, 153-190.

Sumer, B. M., Christiansen, N., and J. Fredsoe. (1992) Time Scale of Scour around a Vertical Pile, Proceedings of the $2^{\text {nd }}$ International Offshore and Polar Engineering Conference, International Society for Offshore and Polar Engineering, 3, 308-315.

Whitehouse, R. J. S. 1998. Scour at Marine Structures: A Manual for Practical Applications, Thomas Telford, London. 